\title{
Test Yourself Question: Enlarging right thigh mass
}

\section{Ban Sharif ${ }^{1} \cdot$ Asif Saifuddin ${ }^{1}$}

Published online: 30 July 2018

(C) ISS 2018

82-year-old female presents with a 3-month history of a rapidly enlarging mass in her right thigh Figs. 1, 2, 3, 4 and 5.
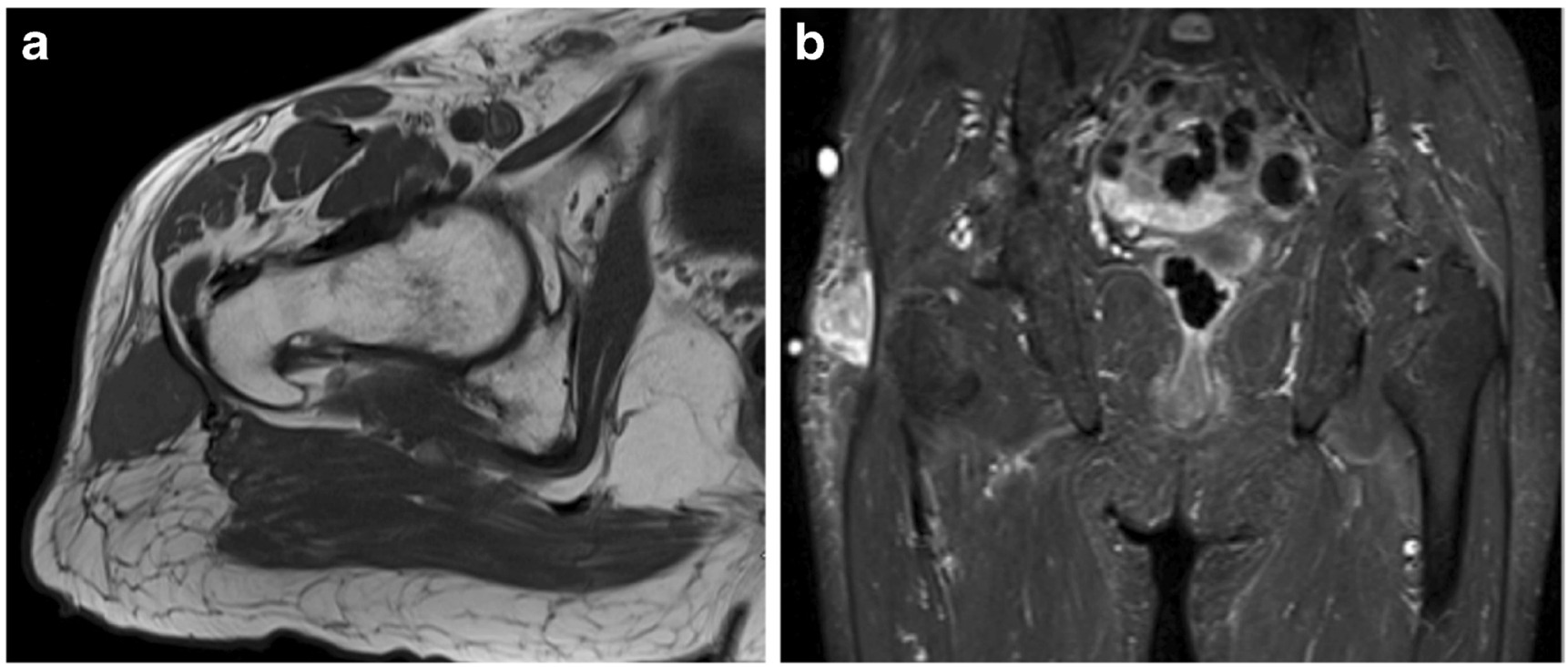

Fig. 1 a Axial T1W FSE MR image. b Coronal STIR MR image

The diagnosis can be found at https://doi.org/10.1007/s00256-018-3031-4

$\triangle$ Ban Sharif

ban.sharif@nhs.net

1 Department of Radiology, Royal National Orthopaedic Hospital, Brockley Hill, Stanmore, Middlesex HA7 4LP, UK 

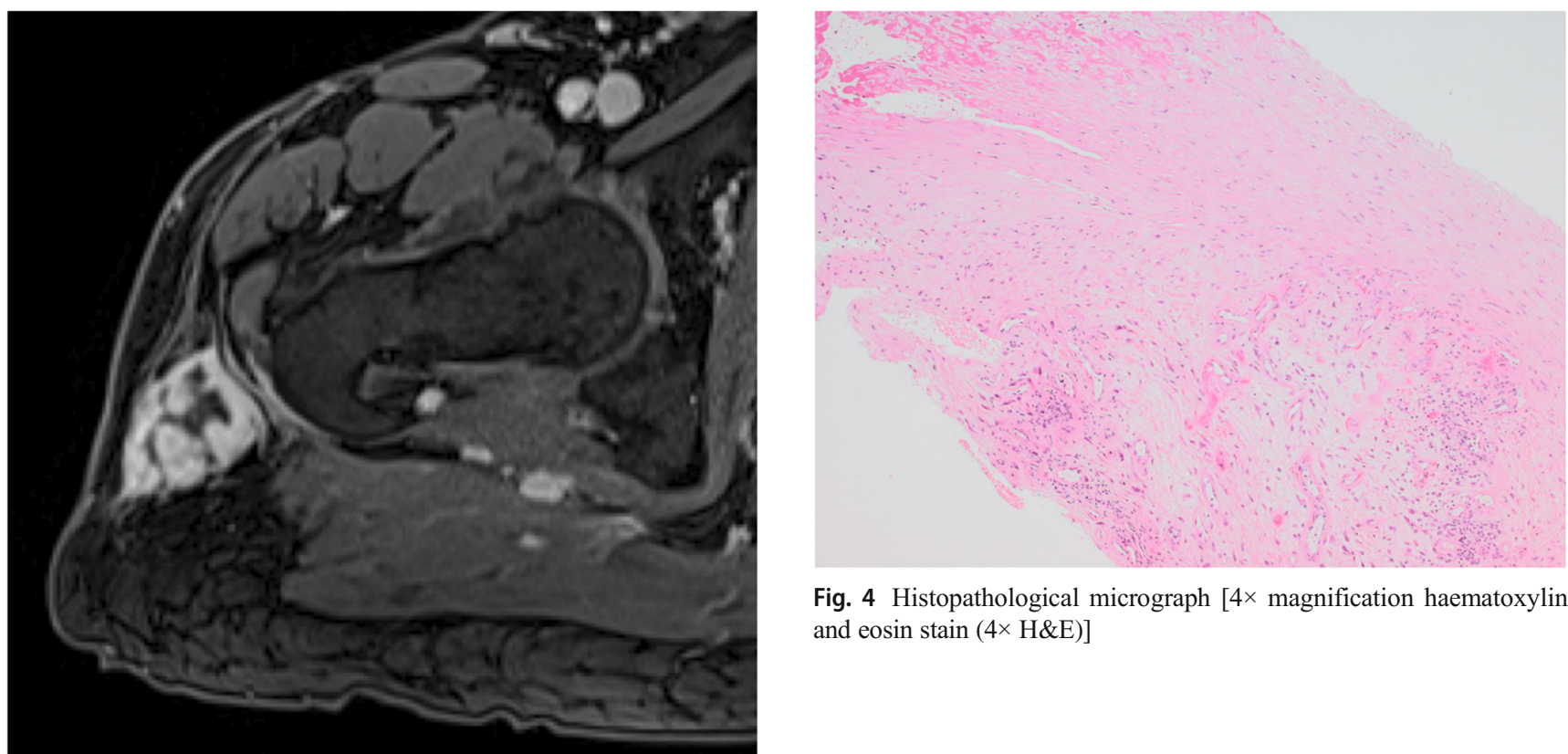

Fig. 4 Histopathological micrograph $[4 \times$ magnification haematoxylin and eosin stain $(4 \times \mathrm{H} \& \mathrm{E})]$

Fig. 2 Axial T1W FS post gadolinium image

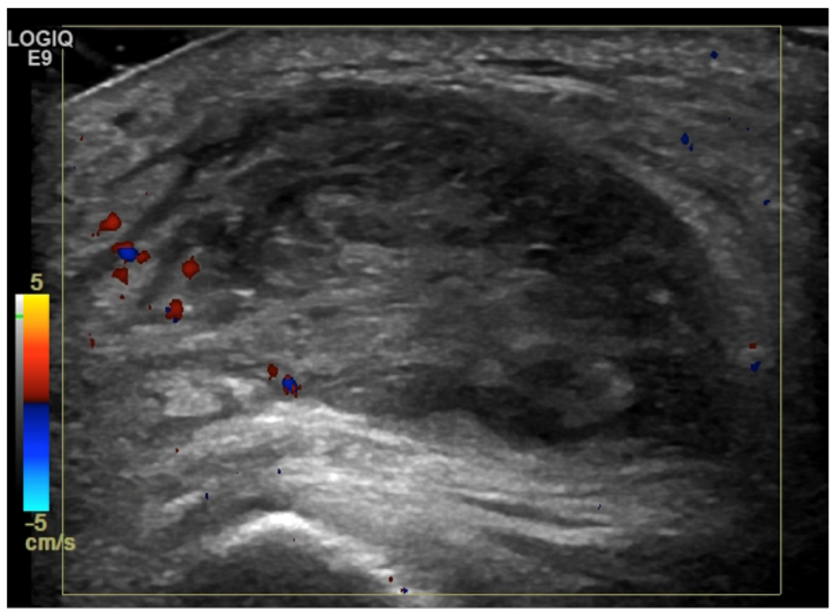

Fig. 3 Static ultrasound image with Doppler flow

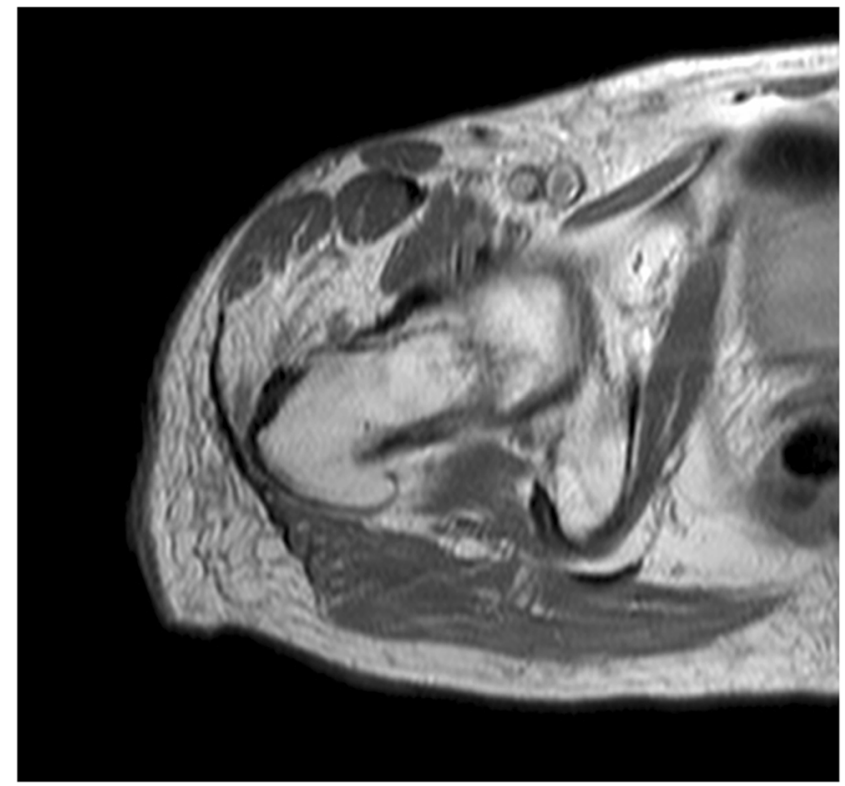

Fig. 5 Axial PDW image performed 21 months after the index MRI scan

\section{Compliance with ethical standards}

Conflict of interest The authors declare that they have no conflict of interest. 